\title{
Measurement of Boundary Conditions - Surface Heat Flux and Surface Temperature
}

\author{
Wei Liu \\ Japan Atomic Energy Agency \\ Japan
}

\section{Introduction}

In order to understand a heat transfer phenomenon, it is sometimes very important to know the change in heat flux and temperature with time or the distribution of the heat flux and temperature on the surface of a heating block. Furthermore, with the development of computational thermal-fluid dynamics, experimental data that are of the CFD level, both spatially and temporally, are needed to validate the simulation results. However, it is difficult to measure the surface heat flux and surface temperature if no sensors are allowed setting on the surface, which may be a disturbance to the phenomenon itself occurring on the surface. This chapter introduces a technique for the measurement of surface temperature and surface heat flux.

\section{Technique for the measurement of surface temperature and surface heat flux}

The technique for the measurement of surface temperature and surface heat flux involves two steps: (1) measurement of the inner block temperatures using special micro temperature sensors, which are placed at a depth of several micrometers beneath the surface; and (2) solving an inverse heat conduction problem (IHCP) to obtain the surface heat flux and surface temperature, by using the measured inner block temperature data. In other words, the introduction of the IHCP enables us to derive the boundary conditions, which include both surface heat flux and surface temperature, without necessitating the use of a sensor on the surface of interest.

\subsection{Inverse heat conduction problem (IHCP)}

When compared to a normal heat conduction problem, that enables us to calculate temperature distributions inside a block by solving the heat conduction equation, with the initial and boundary conditions as input, the IHCP is an analysis method that enables us to calculate the boundary conditions by solving the heat conduction equation with Laplace transform technique, with the initial conditions and inner temperature as input. A considerable number of research studies (Burggraf, 1964; Sparrow et al., 1964; Imber, 1974; Shoji, 1978; Monde, 2003a, 2003b; Woodfield, 2006a, 2006b) have adopted analytical approaches for solving the IHCPs. Although limited to fairly simple geometry, explicit analytical solutions to IHCP have been derived and are very fast computational. If a one(two-) dimensional heating block comprises two unknown boundaries, as shown in Fig. 1, 
then it needs two (rows of) inner-temperature readings to close the heat conduction equation and to obtain the heat fluxes and temperatures on the two boundaries. However, if the heating block has only a single unknown boundary, theoretically, then it needs only a single (line of) inner-temperature reading to close the heat conduction equation. Noting that the recent introduction of new concepts such as moving window (for two rows of measuring data to close two unknown boundary conditions) (Woodfield, 2006a) and superposition of successive corrections in approximating the temperature readings (for one row of measuring data to close one unknown boundary condition) (Woodfield, 2006b) has made the use of the IHCP practical.

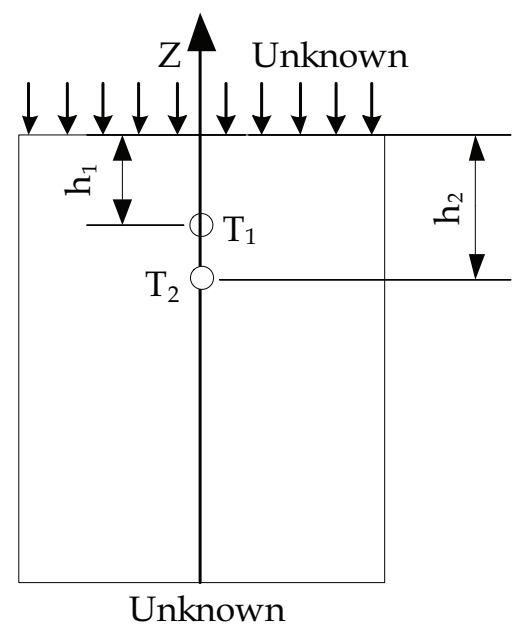

(a) One-dimensional

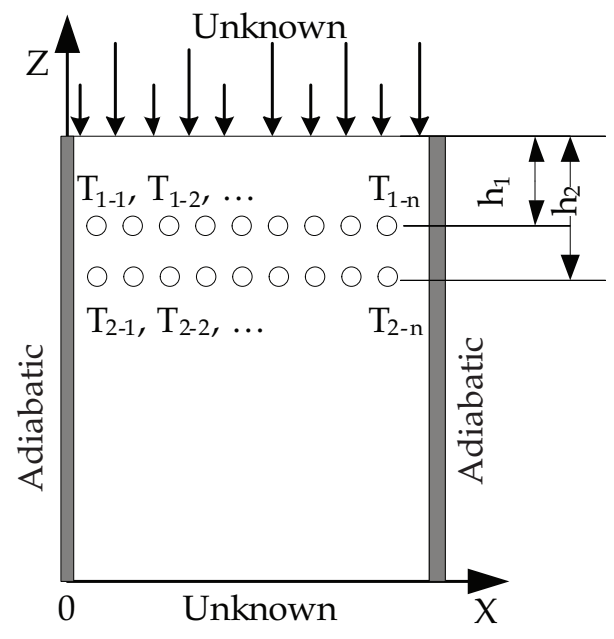

(b) Two-dimensional

Fig. 1. A Heating block with two unknown boundaries

To solve the IHCP accurately, there is a demand for the measured inner temperature data. That is, the data should have sensed the effect of the boundary under study. This necessitates the use of highly sensitive temperature sensors located in close proximity to the surface. This is very important in tracing a fast-changing transient phenomenon. In a highfrequency process such as boiling, the high-frequency effects are strongly damped within the heating block because of the thermal inertia of the heating block. Thus, the temperature sensors must be located as close as possible to the surface of interest. If a sinusoidal heat flux boundary $\mathrm{q}_{0(\omega t)}$ is imposed on one surface of a one-dimensional solid with initial temperature $T_{0}$ and the other surface is kept adiabatic, as shown in Fig. 2, the exact solution for the temperature within the solid is given by Eq. (1) (Carslaw, 2003), where $\lambda$ and $\alpha$ are the thermal conductivity and thermal diffusivity, respectively. Equation (1) clearly shows that the effect of the oscillation diminishes quickly with an increase in the depth into the heating block, which is more pronounced for high frequencies. This sets an upper limit to the frequency of the fluctuations that can be detected by a sensor placed within the heating block. In other words, if a temperature sensor is placed at a distance from the surface, it may be impossible to detect the effects from a high-frequency mode. Further, using the readings taken at that point as the input data of the IHCP will result in the inaccurate prediction of 
the boundary conditions. As an example, a comparison of the surface heat fluxes between the predictions obtained from the Woodfield's analytical approach and the exact values at different frequencies is shown in Fig. 3 (Woodfield, 2006a). In the calculation, copper is used for the heating block and the exact solution calculated from Eq. (1) with h1 $=2 \mathrm{~mm}$ is used as the input data. $\mathrm{h}_{1}=2 \mathrm{~mm}$ represents the depth at which the temperature sensor is placed. As shown in the figure, the agreement between the sine waves of the actual and predicted heat fluxes is remarkably good at low frequencies of 1 and $3 \mathrm{~Hz}$; however, the accuracy decreases as the frequency increases. This means that when the sensor is placed at a depth of $2 \mathrm{~mm}$ beneath the surface, it cannot sense the effect of the surface heat flux with a frequency higher than $5 \mathrm{~Hz}$. Therefore, a new technique through which the temperature sensors can be placed very close to the surface of interest is necessary.

$$
T-T_{0}=\frac{q_{0}}{\lambda} \sqrt{\frac{a}{\omega}} e^{-h_{1} \sqrt{\frac{\omega}{2 a}}} \sin \left(\omega t-h_{1} \sqrt{\frac{\omega}{2 a}}-\frac{\pi}{4}\right)+\frac{2 q_{0} a \omega}{\pi \lambda} \int_{0}^{\infty} \frac{\cos \left(u h_{1}\right)}{\omega^{2}+a^{2} u^{4}} e^{-a u^{2} t} d u
$$

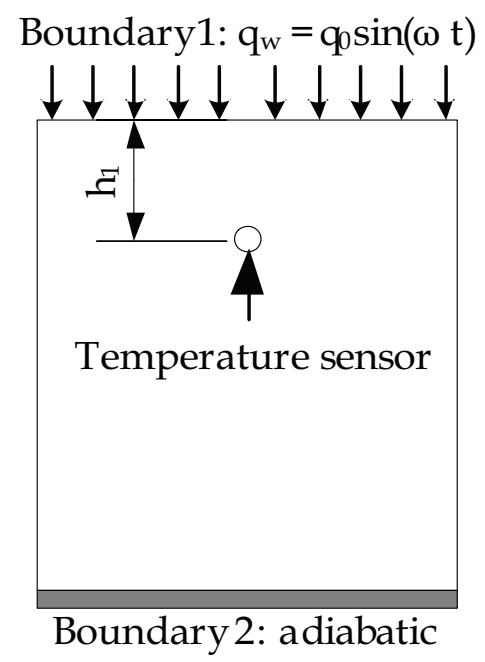

Fig. 2. A One-dimensional block with the sinusoidal heat flux boundary imposed on one surface

\subsection{Special micro temperature sensors}

As already mentioned, in order to accurately calculate the boundary conditions by using the IHCP, the temperature sensors in the heating block should be positioned as close as possible to the surface of interest. Furthermore, in order to determine the distribution of heat flux and temperature on the boundary in detail, we need to solve the two-dimensional IHCP, which requires the temperature sensors to have a high spatial resolution.

We therefore introduced special micron-sized thermocouples that share a single positive pole (Enomoto \& Furuhama, 1984; Buchholz et al., 2004; Liu \& Takase, 2009). A schematic illustration of the thermocouples is shown in Fig. 4. In a heating block made of copper, the temperature junctions are located at multiple points from No. 1 to No. N. Each junction has 
a constantan wire as its negative pole, but shares a common positive pole made of copper. The temperature sensors are thus of the T-type. The common positive pole can be formed by using a film-formation technique - such as sputtering - after the constantan wires are set into the copper block. The thickness of the sputtering film can be controlled accurately within several micrometers. This means that the temperature junctions can be formed at a depth of several microns beneath the surface of interest.

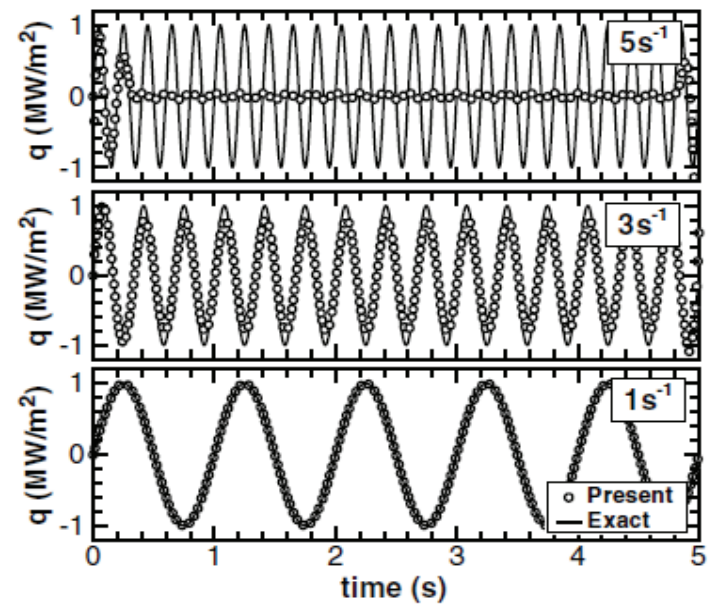

Fig. 3. Effect of inner-temperature measuring position on the accuracy of the IHCP predictions (temperature measured at a depth of $2 \mathrm{~mm}$ beneath the surface is used as the input of IHCP, (Woodfield, 2006a))

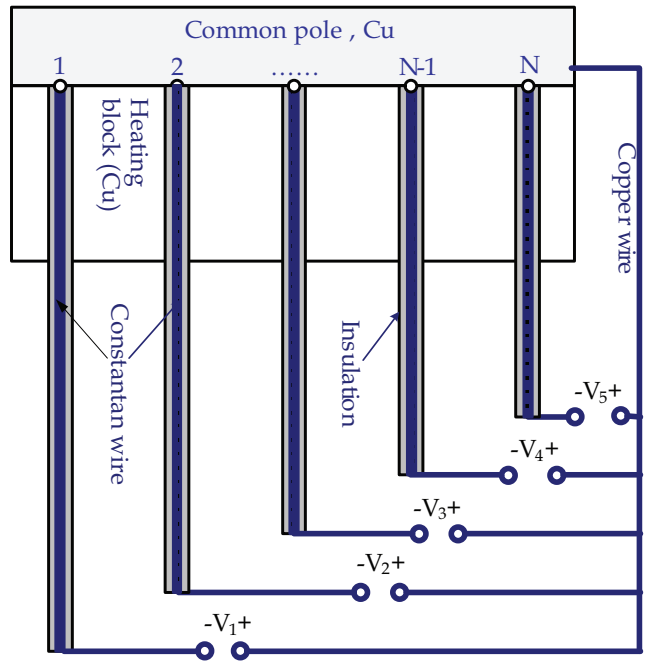

Fig. 4. Schematic illustration of the special micron-sized T-type thermocouples that share a single positive pole 
By using teflon-coated $(76 \mu \mathrm{m})$ and polyimide-coated $(50 \mu \mathrm{m})$ constantan wires, we succeeded in developing temperature sensors with a pitch of $0.5 \mathrm{~mm}$ and at depth of 3.1 $\mu \mathrm{m}$, and temperature sensors with a pitch of $0.16 \mathrm{~mm}$ and at a depth of $1.3 \mu \mathrm{m}$, respectively, beneath the surface of interests. Figure 5 shows a comparison between the imposed sinusoidal heat flux and the sinusoidal heat flux predicted from the IHCP on the basis of the temperature calculated using Eq. (1) with $h_{1}=3.1 \mu \mathrm{m}$. As shown in the figure, there is a very good agreement between the imposed and predicted sinusoidal heat fluxes at the frequencies of 20 and $50 \mathrm{~Hz}$. These cases correspond to the bubble frequencies under subcooled and saturated atmospherical pressure pool boiling conditions, respectively. The figure theoretically clarifies that the high-frequency changed boundary conditions can be traced by using the temperature sensor located at a depth of $3.1 \square \mathrm{m}$ beneath the surface.

The new sensors are of the wire type and are therefore highly sensitive. With sharing a common positive pole, the number of wiring lines is decreased and it is easier to obtain a high spatial resolution. The response time of the sensors is assumed to be zero. These characteristics, together with the fact that temperature junctions can be easily placed several microns beneath the surface, contribute to the effectiveness of the IHCP technique in tracing the boundary conditions.

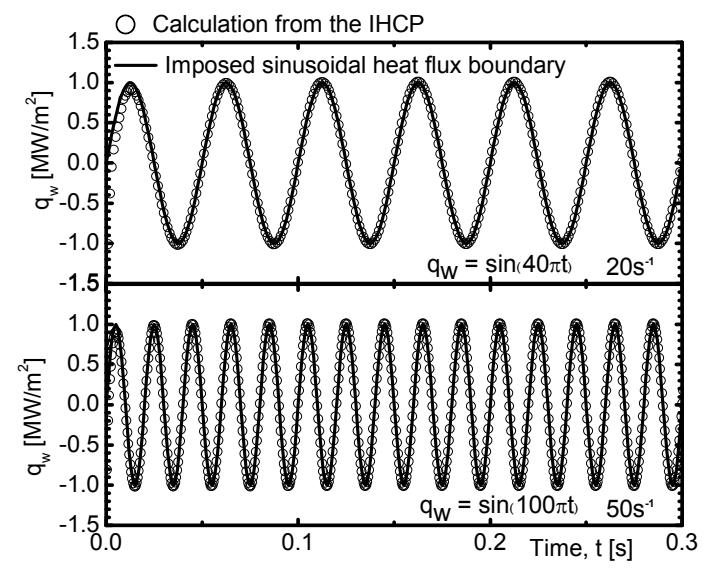

Fig. 5. Effect of inner-temperature measuring position on the accuracy of the IHCP predictions (temperature measured at a depth of $3.1 \mu \mathrm{m}$ beneath the surface is used as the input of IHCP)

Note that as shown in Fig. 1, the standard IHCP requires the sensors to be placed at two different depths. However, in the case where only one boundary is unknown (with the adiabatic or semi-infinite assumption valid on the other boundary), only one row of sensors is required in order to obtain the boundary conditions about the surface of interest. This is highly desirable since the overall cost incurred when allocating the sensors is reduced. As recommended by Woodfield, if the Fourier number $\frac{a t}{H^{2}}<0.1$, where $\mathrm{H}$ is the thickness of the heating block, then for practical use, the block can be treated as being semi-infinite. Further, note that the thin copper film, which acts as the common pole of the temperature sensors, is to be coated with a protection film to prevent it from oxidation. Selection of the type of protection film is very important for the realization of durable temperature sensors. 


\section{Measurement example}

The above mentioned measurement technique was successfully used in the measurement of the surface heat flux and surface temperature during a boiling process. The experimental apparatus used is shown in Fig. 6. It includes a boiling vessel and a heating block. The heating block is made of copper and is peripherally insulated. The heating block is composed of two parts, upper and lower. The image of the upper part is shown in Fig. 7, in which 10 special micro temperature sensors are placed radially at a pitch of $0.5 \mathrm{~mm}$ and at a depth of $3.1 \mu \mathrm{m}$ from the boiling surface. The upper and lower parts of the heating block are joined together by using a high-temperature adhesive. A cartridge heater is inserted into the lower heating block.

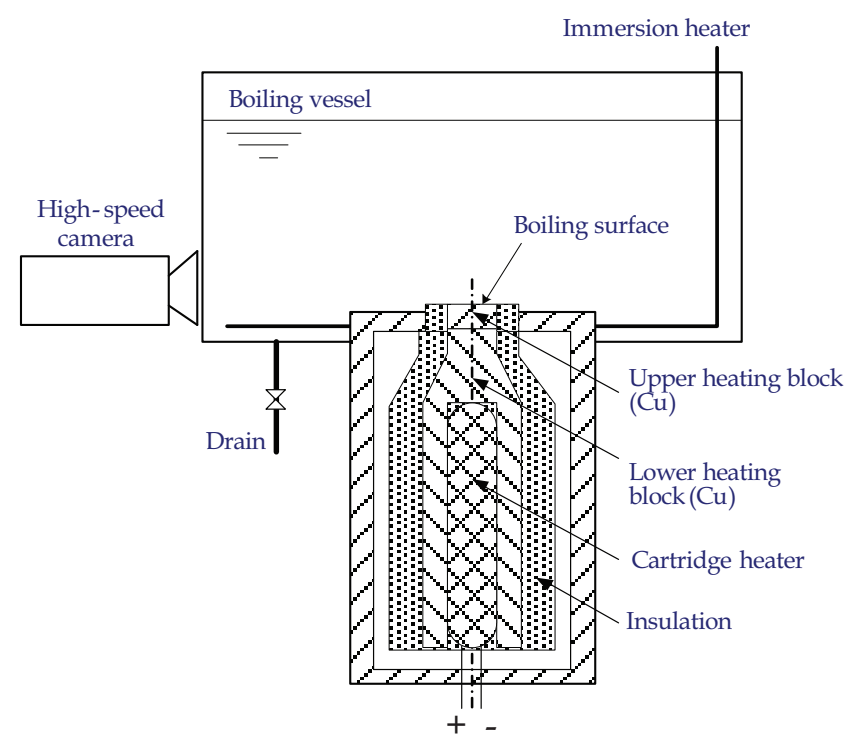

Fig. 6. Experimental apparatus

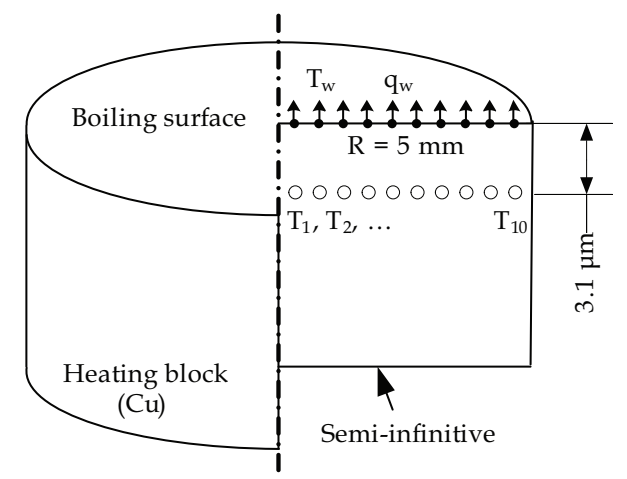

Fig. 7. The upper heating block 
The data collected by two micron-sized thermocouples that share a common positive pole are shown in Fig. 8. In the figure, $\mathrm{T}_{4}$ and $\mathrm{T}_{10}$ are the temperatures measured at the same depth but at different radial positions. The figure shows that the thermocouples are effective in measuring the temperatures. The data taken at $\mathrm{T}_{4}$, which is just below a bubble, were used as the input data for solving a semi-infinite one-dimensional IHCP in order to obtain the surface heat flux and surface temperature, the results of which are shown in Fig. 9. The peak of the heat flux corresponds to the formation of a large, deformed bubble.

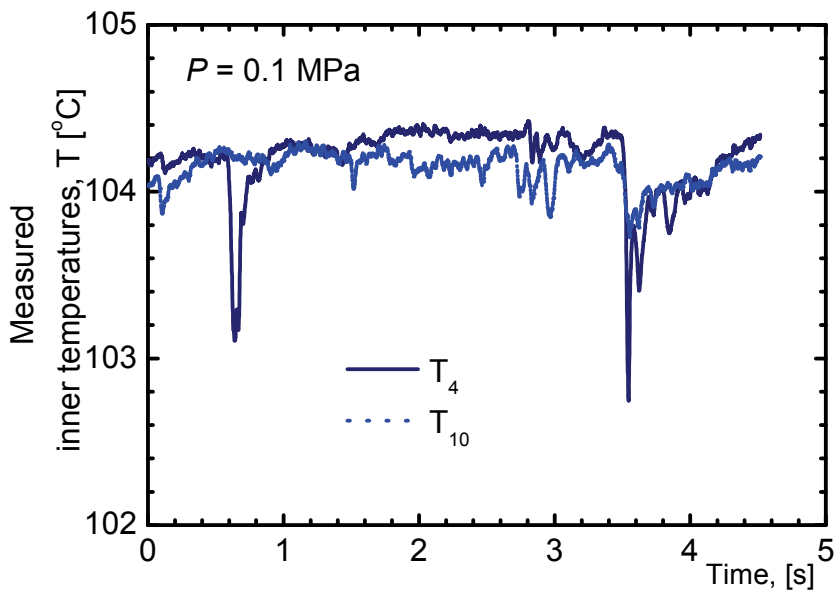

Fig. 8. Temperatures measured during the boiling processes by the micron-sized thermocouples sharing a common positive pole

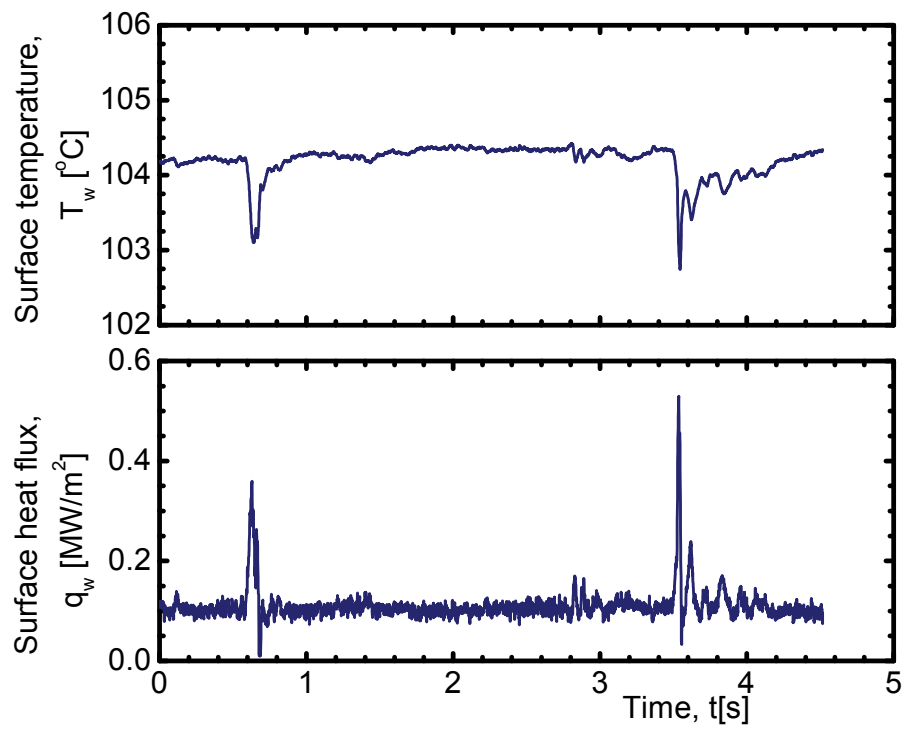

Fig. 9. Measured surface heat flux and surface temperature during the boiling process 


\section{Conclusions}

In this chapter, a technique for the measurement of surface temperature and surface heat flux was introduced. This technique involves two steps: (1) measurement of the inner block temperatures near the surface using special micro temperature sensors; and (2) solving an IHCP to obtain the surface heat flux and surface temperature by using the measured inner block temperature data as input. For the inner block temperature measurement, special Ttype temperature sensors with a common positive pole were introduced. By using the film formation technique of sputtering, the temperature junctions can be placed at a depth of several micrometers beneath the surface of interest.

The developed system was used to determine the change in the surface heat flux and surface temperature during a boiling process. The results from the experiments showed that the special T-type micro temperature sensors can effectively trace the temperature change during a boiling process. By using the measured inner temperatures, one-dimensional IHCP was solved to obtain the surface heat flux and surface temperature. The increase in the surface heat flux with the formation of big bubbles was calculated successfully.

\section{References}

Buchholz M., Luttich T., Auracher H., Marquardt W., (2004). Experimental investigation of local process in pool boiling along the entire boiling curve, Int. J. Heat Fluid, Vol. 25, 243 -261

Burggraf, O.R., (1964). An exact solution of the inverse problem in heat conduction theory and applications, ASME J. Heat Transfer, Vol. 86, 373-382

Carslaw H.S., Jaeger J.C., Conduction of Heat in Solids, Oxford University Press, 2003.

Enomoto Y. \& Furuhama S., (1984). Research on thin film thermocouple for transient surface temperature measurement in internal combustion engine, Transactions of Japan Society of Mechanical Engineering, series B, Vol.50, No.453, 1353-1362, (In Japanese).

Imber M., (1974). Temperature extrapolation mechanism for two-dimensional heat flow, AIAA J. Vol.12, No.8, 1089-1093

Liu W. \& Takase K. (2009). Measurement of surface heat flux and surface temperature in Nucleate Pool Boiling Using Micro-Thermocouples, Proceedings of the 17th International Conference on Nuclear Engineering, ICONE17-75880

Monde M., Arima H. \& Mitsutake Y., (2003a) Estimation of surface temperature and heat flux using inverse solution for one-dimensional heat conduction, ASME J. Heat Transfer, Vol .125, 213-223.

Monde M., Arima H., Liu W., Mitsutake Y. \& Hammad J.A., (2003b). An analytical solution for two-dimensional inverse heat conduction problems using Laplace transform, Int. J. Heat Mass Transfer, Vol. 46, 2135-2148

Shoji M. (1978). Study of inverse problem of heat conduction, Transactions of Japan Society of Mechanical Engineering, series B, Vol. 44, No.381, 1633-1643 (in Japanese).

Sparrow E.M., Haji-Sheikh A. \& Lundgren T.S., (1964). The inverse problem in transient heat conduction, ASME J. Appl. Mech., Vol. 31, 369-375

Woodfield P.L., Monde M. \& Mitsutake Y., (2006a). Implementation of an analytical inverse heat conduction technique to practical problems, Int. J. Heat Mass Transfer, Vol. 49, 187-197.

Woodfield P.L., Monde M., Mitsutake Y., (2006b). Improved analytical solution for inverse heat conduction problems on thermally thick and semi-infinite solids, Int. J. Heat Mass Transfer, Vol. 49, 2864-2876. 


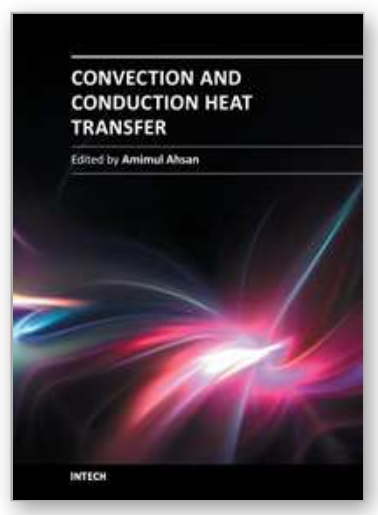

\section{Convection and Conduction Heat Transfer}

Edited by Dr. Amimul Ahsan

ISBN 978-953-307-582-2

Hard cover, 394 pages

Publisher InTech

Published online 17, October, 2011

Published in print edition October, 2011

The convection and conduction heat transfer, thermal conductivity, and phase transformations are significant issues in a design of wide range of industrial processes and devices. This book includes 18 advanced and revised contributions, and it covers mainly (1) heat convection, (2) heat conduction, and (3) heat transfer analysis. The first section introduces mixed convection studies on inclined channels, double diffusive coupling, and on lid driven trapezoidal cavity, forced natural convection through a roof, convection on non-isothermal jet oscillations, unsteady pulsed flow, and hydromagnetic flow with thermal radiation. The second section covers heat conduction in capillary porous bodies and in structures made of functionally graded materials, integral transforms for heat conduction problems, non-linear radiative-conductive heat transfer, thermal conductivity of gas diffusion layers and multi-component natural systems, thermal behavior of the ink, primer and paint, heating in biothermal systems, and RBF finite difference approach in heat conduction. The third section includes heat transfer analysis of reinforced concrete beam, modeling of heat transfer and phase transformations, boundary conditions-surface heat flux and temperature, simulation of phase change materials, and finite element methods of factorial design. The advanced idea and information described here will be fruitful for the readers to find a sustainable solution in an industrialized society.

\section{How to reference}

In order to correctly reference this scholarly work, feel free to copy and paste the following:

Wei Liu (2011). Measurement of Boundary Conditions - Surface Heat Flux and Surface Temperature, Convection and Conduction Heat Transfer, Dr. Amimul Ahsan (Ed.), ISBN: 978-953-307-582-2, InTech, Available from: http://www.intechopen.com/books/convection-and-conduction-heat-transfer/measurement-ofboundary-conditions-surface-heat-flux-and-surface-temperature

\section{INTECH}

open science | open minds

\author{
InTech Europe \\ University Campus STeP Ri \\ Slavka Krautzeka 83/A \\ 51000 Rijeka, Croatia \\ Phone: +385 (51) 770447 \\ Fax: +385 (51) 686166 \\ www.intechopen.com
}

\author{
InTech China \\ Unit 405, Office Block, Hotel Equatorial Shanghai \\ No.65, Yan An Road (West), Shanghai, 200040, China \\ 中国上海市延安西路65号上海国际贵都大饭店办公楼 405 单元 \\ Phone: +86-21-62489820 \\ Fax: $+86-21-62489821$
}


(C) 2011 The Author(s). Licensee IntechOpen. This is an open access article distributed under the terms of the Creative Commons Attribution 3.0 License, which permits unrestricted use, distribution, and reproduction in any medium, provided the original work is properly cited. 